\section{Three Japanese patients with congenital pituitary hormone deficiency and ophthalmological anomalies}

\author{
Kuniko Takanashi,1 Yashuto Suzuki,1 \\ Ayumu Noro, 1 Minako Sugiyama, ${ }^{1}$ \\ Masanori Nakanishi, 1 \\ Tetsuro Nagashima, ${ }^{1}$ Akie Nakamura,2 \\ Ishizu Katsura,2 Toshihiro Tajima1 \\ 1Department of Pediatrics, Kushiro Red \\ Cross Hospital, Kushiro; ${ }^{2}$ Department \\ of Pediatrics, Hokkaido University School \\ of Medicine, Sapporo, Japan
}

\section{Abstract}

The clinical phenotype of congenital pituitary hormone deficiency is variable and can be associated with a number of structural abnormalities of the central nervous system. We report three Japanese patients with congenital pituitary hormone deficiency and ophthalmological anomalies. Two of the patients initially showed strabismus and unilateral optic nerve hypoplasia. Thereafter, growth failure became evident, leading to the diagnosis of pituitary hormone deficiency. The other patient had severe congenital hypopituitarism with respiratory distress and hypoglycemia from the first day of life. In addition, he had prolonged jaundice and impaired liver function with bilateral optic nerve hypoplasia. Neuroimaging of the pituitary region in all three patients demonstrated a small anterior pituitary lobe and no pituitary stalk. Our findings indicate that clinical variability of congenital hypopituitarism must be considered. In a patient with ophthalmological symptoms, endocrine evaluation and neuroimaging of the CNS including the pituitary region should be considered.

\section{Introduction}

The anterior pituitary gland is the primary site of endocrine regulation of reproduction and stress response. Congenital defects of the pituitary gland can cause pituitary hormone deficiency, resulting in hypopituitarism and a variable clinical phenotype.1-3 In severe hypopituitarism, major clinical symptoms include respiratory distress, hypotonia, hypoglycemia, and cholestatic jaundice, which manifest soon after birth. Thus, early diagnosis and intervention for severe cases are crucial since patients undergo severe hypoglycemia and adrenal and thyroid insufficiency that may affect neurological development and survival. ${ }^{1-5}$ In mild cases, patients may be diagnosed much later when growth failure becomes prominent. ${ }^{1-3}$

Congenital hypopituitarism can be associated with a number of structural abnormalities in the central nervous system (CNS) with ophthalmological malformations.1,2 Septo-optic dysplasia (SOD) patients may show a complication of hypopituitarism..$^{5-8}$ In addition, mutations of transcription factors may cause anophthalamia/microophthalamia and hypopituitarism. $1,2,8-10$ Here, we report clinical and brain magnetic resonance imaging (MRI) of three Japanese patients with congenital pituitary hormone deficiency and ophthalmological abnormalities.

\section{Materials and Methods}

\section{Pituitary hormone assessment}

$\mathrm{GH}$ provocative tests were performed using insulin (0.05 IU/kg) and arginine $(0.5 \mathrm{~g} / \mathrm{kg})$. Serum levels of TSH were determined in response to TRH $(5 \mu \mathrm{g} / \mathrm{kg})$. Serum cortisol was determined in response to the insulin (0.05 $\mathrm{IU} / \mathrm{kg}$ ) tolerance test. Serum levels of LH and FSH were determined in response to $\mathrm{GnRH}(2 \mu \mathrm{g} / \mathrm{kg})$.

\section{Case Reports}

\section{Case \#1}

The patient is an 8 year old Japanese girl. She was born after 40 weeks gestation by normal vaginal delivery and was the first child of nonconsanguineous parents. The patient had no siblings, and her parents were healthy. Her birth weight was $3290 \mathrm{~g}$ and length was $49 \mathrm{~cm}$. At 2 days after birth, she developed noncholestatic jaundice and was treated with ultraviolet light for two days. At 6 months of age, strabismus was noted. Ophthalmological evaluation and computed tomography (CT) revealed right optic nerve hypoplasia. At 4 years 8 months she was referred to our hospital because of short stature. On physical examination, her height was $92.6 \mathrm{~cm}$ ( -2.76 SD for a normal Japanese girl) and her weight was 13.6 $\mathrm{kg}$ (-1.8SD for normal Japanese girl). Her psychomotor development was within normal range.

Endocrinological evaluation is summarized in Table 1. She had low serum levels of IGF-1 ( $2.75 \mathrm{nmol} / \mathrm{L}$; normal range of $4.5-31.1$ for a 3 to 5 year old normal Japanese girl), and impaired $\mathrm{GH}$ response on arginine and insulin (0.05 IU/kg) testing. Her thyroid hormone levels were low limit of normal range, suggesting mild central hypothyroidism. MRI showed a
Correspondence: Toshihiro Tajima, Department of Pediatrics, Hokkaido University School of Medicine, N15, W7, Sapporo, Japan 060-0835. Tel:+81.11.706.5954 - Fax: +81.11.70607898.

E-mail: tajeari@med.hokudai.ac.jp

Key words: optic nerve hypoplasia, isolated $\mathrm{GH}$ deficiency, hypopitutarism, septo-optic dysplasia.

Conflict of interest: the authors report no conflicts of interest.

Received for publication: 7 April 2011.

Revision received: 28 June 2011.

Accepted for publication: 1 July 2011.

This work is licensed under a Creative Commons Attribution NonCommercial 3.0 License (CC BYNC 3.0).

(C) Copyright K. Takanashi et al., 2011

Licensee PAGEPress, Italy

Pediatric Reports 2011; 3:e20

doi:10.4081/pr.2011.e20

hypoplastic anterior pituitary gland, no stalk, and an absence of the septum pellucidum (Figure 1A). The posterior pituitary bright spot was not clear. Based on these findings, she was diagnosed as having SOD. Diameters of the optic nerve of the retrobulbar region in the MRI at 7 years 6 months were as follows; right was $3.04 \mathrm{~mm}$ and left was $6.05 \mathrm{~mm}$. With the administration of recombinant human $\mathrm{GH}$, IGF-1 levels increased to the normal range, and the patient showed successful catch-up growth. Regarding thyroid function after $\mathrm{GH}$ replacement, we have carefully monitored.

\section{Case \#2}

The patient is now a 4 year old Japanese girl born after 40 weeks gestation by normal vaginal delivery. Her birth weight was $3000 \mathrm{~g}$ and length was $48 \mathrm{~cm}$. There was no family history of growth disorders. At 3 and 5 days after birth, she had non-cholestatic jaundice requiring phototherapy. At 5 months of age, she showed strabismus and was diagnosed as having right optic nerve hypoplasia (Figure 1B). At 2 years 6 months of age, she was referred to us because of proportionate short stature. On admission, her height was $79.8 \mathrm{~cm}$ (-2.77 SD for a normal Japanese girl) and body weight $9.5 \mathrm{~kg}$ (-2.0 SD for a normal Japanese girl). She had a small anterior pituitary and ectopic posterior pituitary (Figure 1C). Diameters of the optic nerve of the retrobulbar region were measured (right $3.15 \mathrm{~mm}$ and left $5.14 \mathrm{~mm}$ ).

Endocrinological findings demonstrated that she had somatotroph, corticotroph, and thyrotroph deficiencies (Table 1), and, thus, hydrocortisone, L-thyroxine, and $\mathrm{GH}$ replacement were initiated. She presented catch-up growth with a first-year height increment of 0.8 SDS. 


\section{Case \#3}

The patient is now a 5 year old Japanese boy. He was born to unrelated healthy parents by normal vaginal delivery. He had no asphyxia and his birth weight and height were $2780 \mathrm{~g}$ and $47.0 \mathrm{~cm}$, respectively. Four hours after birth he presented with apnea and cyanosis and was found to be hypoglycemic $(0.23 \mathrm{mmol} / \mathrm{L})$. He had a small penis $(1.9 \mathrm{~cm})$ and the bilateral testis were small $(1 \mathrm{~mm} \times 1.5 \mathrm{~mm})$. The hypoglycemia disappeared with continuous infusion of glucose. Thereafter, he suffered from failure to thrive, cholestatic hyperbilirubinemia and hepatomegaly. Liver function tests were altered (peak ALT 117 U/L, AST 100 U/L, $\gamma$-GTP $350 \mathrm{U} / \mathrm{L}$ ) and did not normalize. At 21 days after birth, it became evident that his bilateral eyes could not focus. At this time, brain MRI showed bilateral optic nerve hypoplasia (height of optic chiasm, $1.21 \mathrm{~mm}$ ), no pituitary stalk, a small anterior pituitary gland, and an ectopic posterior pituitary lobe. Endocrine investigations at 1 month of age demonstrated deficiencies in GH, TSH, LH/FSH and cortisol (Table 1). He was treated with hydrocortisone, L-thyroxine, and $\mathrm{GH}$, and showed improvement of liver function and failure to thrive. Since treatment, he has grown well (105.2 m, 0 SD for normal Japanese boy). His psychomotor development is normal.

\section{Discussion}

In this study, we report three patients with congenital pituitary hormone deficiency and ophthalmological abnormalities.

Case \#1 had unilateral optic nerve hypoplasia and an absent septum pellucidum with isolated GH deficiency. She was diagnosed as having SOD. Approximately $60 \%$ of patients with SOD have some degree of pituitary hormone deficiency, and the most common endocrine defect is GH deficiency followed by TSH and ACTH deficiency. ${ }^{3,5}$ Our case 1 showed isolated GH deficiency. However, as other hormone deficiencies may appear with age, 3,5 regular evaluation of other pituitary hormones is necessary.

Cases \#2 and \#3 had combined pituitary hormone deficiency, and the degree of hypopituitarism was most severe in case \#3. Therefore, case \#3 showed several manifestations from the neonatal period. Early diagnosis of hypopituitarism in the neonatal period is difficult because of factors such as prematurity and related neonatal complications. Indeed, it has been reported that approximately 50\% of patients with congenital pituitary hormone deficiency may have clinical features such as respiratory distress, hypoglycemia, hyponatremia, and jaundice. However, a correct diagnosis is made in the neonatal period in only
Table 1. Hormone deficiency profiles of the patients

\begin{tabular}{|c|c|c|c|c|}
\hline $\begin{array}{l}\text { Patient (Sex) } \\
\text { Age at evaluation }\end{array}$ & $\begin{array}{c}1 \text { (Female) } \\
4.8 \mathrm{yr}\end{array}$ & $\begin{array}{c}2 \text { (Female) } \\
3.6 \mathrm{yr}\end{array}$ & $\begin{array}{l}3 \text { (Male) } \\
1 \text { month }\end{array}$ & Normal range \\
\hline \multicolumn{5}{|l|}{ Insulin $(0.05 \mathrm{U} / \mathrm{kg})^{\mathrm{a}}$} \\
\hline \multicolumn{5}{|l|}{ Blood glucose $(\mathrm{mmol} / \mathrm{L})$} \\
\hline Before stimulation & 4.71 & 4.44 & 5.10 & \\
\hline After stimulation & 2.33 & 2.11 & 2.66 & \\
\hline \multicolumn{5}{|l|}{$\mathrm{GH}(\mathrm{g} / \mathrm{L})$} \\
\hline Basal & 0.28 & 0.36 & 0.78 & $>6.0^{\mathrm{b}}$ \\
\hline Peak & 1.38 & 1.19 & 2.01 & \\
\hline \multicolumn{5}{|l|}{ Arginine $(0.5 \mathrm{~g} / \mathrm{kg})$} \\
\hline \multicolumn{5}{|l|}{$\mathrm{GH}(\mathrm{g} / \mathrm{L})$} \\
\hline Basal & 0.54 & 0.57 & 1.2 & \\
\hline Peak & 1.53 & 2.69 & 2.33 & $>6.0^{\mathrm{b}}$ \\
\hline IGF-1 (mnol/L) & 2.75 & 1.3 & 2.99 & $\begin{array}{l}4.58 \sim 31.1 \mathrm{c} \\
235 \sim 19 \text { d }^{\mathrm{d}}\end{array}$ \\
\hline FT4 $(\mathrm{pmol} / \mathrm{L})$ & 13.0 & 11.0 & 9.90 & $12.9 \sim 25.0$ \\
\hline FT3 $(\mathrm{pmol} / \mathrm{L})$ & 6.16 & 3.62 & 4.72 & $3.43 \sim 8.16$ \\
\hline \multicolumn{5}{|l|}{ TRH (5 $\mu \mathrm{g} / \mathrm{kg})$} \\
\hline Basal & 2.86 & 2.63 & 2.77 & $0.1 \sim 5.0$ \\
\hline Peak & 11.03 & $22.70 \mathrm{e}$ & $26.3^{\mathrm{e}}$ & $10.0 \sim 35.0$ \\
\hline \multicolumn{5}{|l|}{ Insulin (0.05 U/kg) } \\
\hline \multicolumn{5}{|l|}{ Cortsiol (nmol/L) } \\
\hline Basalf $^{\mathrm{C}}$ & 217.3 & 223.2 & 129.3 & $138.0 \sim 551.8$ \\
\hline Peak & 300.4 & 268.7 & 245.6 & $275.9 \sim 965.6$ \\
\hline \multicolumn{5}{|l|}{ GnRH (2 g/kg) } \\
\hline \multicolumn{5}{|l|}{ LH (IU/L) } \\
\hline Basal & 0.09 & 0.09 & 0.05 & $0.03 \sim 1.4$ \\
\hline Peak & 3.01 & 2.11 & 1.2 & $1.81 \sim 10.5$ \\
\hline \multicolumn{5}{|l|}{ FSH (IU/L) } \\
\hline Basal & 5.00 & 2.25 & 1.1 & $0.51-4.03$ \\
\hline Peak & 21.67 & 8.73 & 3.75 & $8.23 \sim 35.2$ \\
\hline
\end{tabular}

aThe dose of insulin $(0.05 \mathrm{IU} / \mathrm{kg})$ effectively decreased blood glucose levels in the three patients; bserum GH was determined using a recombinant GH standard, and, thus, the peak GH values after stimulation is less than $6 \mathrm{~g} / \mathrm{L}$ are used for GH deficiency; cfrom 3 to 5 year old Japanese girl. d From 0 to 1 year old Japanese boy; etheir serum TSH levels showed delayed decline $(22.7$ and $26.3 \mathrm{mIU} / \mathrm{L}$ at 120 min after TRH stimulation, respectively); fobtained at around 0800-0830 h.
(A)

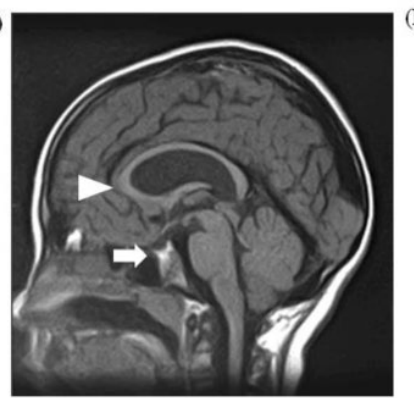

(C)

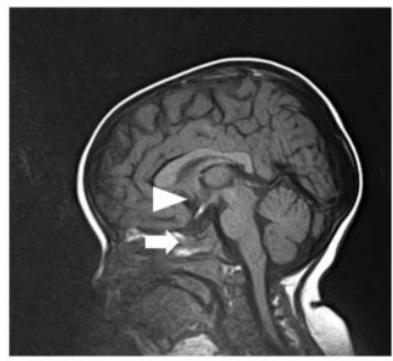

(B)

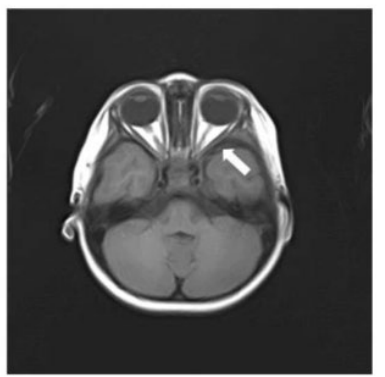

(D)

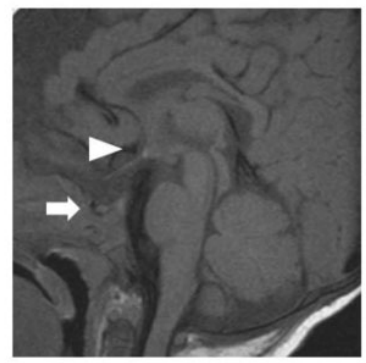

Figure 1. (A) A sagittal T1-weighted magnetic resonance image showing a small anterior pituitary (arrow) and the absence of the septum pellucidum (arrow head) in case 1. (B) computed tomography demonstrated right optic nerve hypoplasia (arrow) in case 2. (C) A sagittal T1-weighted magnetic resonance image showing a hypoplastic anterior pituitary and an ectopic posterior lobe in case 2. (D) A sagittal T1-weighted magnetic resonance image showing a hypoplastic anterior pituitary and an ectopic posterior lobe in case 3 . 
$23 \%$ of cases. 11 Therefore, congenital hypopituitarism is rare, although it is a differential diagnosis of severe neonatal complications.

Sobrier et al. ${ }^{12}$ have reported two patients with a pituitary aplasia, but normally located posterior pituitary and no optic nerve abnormalities. These two patients showed severe respiratory distress and hypoglycemia during the first day of life. In these two patients, mutations of HESX1 gene, which is the transcription factor involving pituitary development, were identified. This study indicates that genetic investigation is important for genetic counseling for severe congenital hypopituitarism. Thus, the genetic causes of our patients must be further studied.

Prolonged jaundice is a clinical manifestation of congenital pituitary hormone deficiency. Indirect hyperbilirubinemia is usually caused by thyroxine deficiency. Furthermore, since cortisol deficiency is thought to reduce bile acid production and flow, direct hyperbilirubinemia and impaired liver function may occur.4,13 Thus, the severe cortisol deficiency in case 3 can explain impaired liver function and cholestasis. In conclusion, the clinical variability of congenital hypopituitarism must be considered in diagnosis. Additionally, if ophthalmological symptoms are observed, endocrine evaluation and neuroimaging of the CNS including the pituitary region should be considered.

\section{References}

1. Cohen LE, Radovick S. Molecular basis of combined pituitary hormone deficiencies. Endocr Rev 2002;23:431-42.

2. Kelberman D, Dattani MT. The role of transcription factors implicated in anterior pituitary development in the aetiology of congenital hypopituitarism. Ann Med 2006;38:560-77.

3. Alatzoglou KS, Dattani MT. Genetic forms of hypopituitarism and their manifestation in the neonatal period. Early Hum Dev 2009;85:705-12.

4. Scommegna S, Galeazzi D, Picone S, et al. Neonatal identification of pituitary aplasia: a life-saving diagnosis. Review of five cases. Horm Res 2004;62:10-6.

5. Mehta A, Hindmarsh PC, Mehta H, et al. Congenital hypopituitarism: clinical, molecular and neuroradiological correlates. Clin Endocrinol 2009;71:376-82.

6. Webb EA, Dattani MT. Septo-optic dysplasia. Eur J Hum Genet 2010;18:393-7.

7. Dattani MT, Martinez-Barbera JP, Thomas $\mathrm{PQ}$, et al. Mutations in the homeobox gene HESX1/Hesx1 associated with septo-optic dysplasia in human and mouse. Nat Genet 1998;19:125-33.

8. Tajima T, Hattorri T, Nakajima T, et al. Sporadic heterozygous frameshift muta- tion of HESX1 causing pituitary and optic nerve hypoplasia and combined pituitary hormone deficiency in a Japanese patient. J Clin Endocrinol Metab 2003;88:45-50.

9. Tajima T, Ohtake A, Hoshino M, et al. OTX2 loss of function mutation causes anophthalmia and combined pituitary hormone deficiency with a small anterior and ectopic posterior pituitary. J Clin Endocrinol Metab 2009;94:314-9.

10. Dateki S, Kosaka K, Hasegawa K, et al. J Clin Endocrinol Metab. 2010 ;95:756-64.

11. Mehta A, Hindmarsh PC, Dattani MT. An update on the biochemical diagnosis of congenital ACTH insufficiency. Clin Endo crinol 2005;62:307-14.

12. Sobrier ML, Maghnie M, Vié-Luton MP, et al. Novel HESX1 mutations associated with a life-threatening neonatal phenotype, pituitary aplasia, but normally located posterior pituitary and no optic nerve abnormalities. J Clin Endocrinol Metab 2006;91: 4528-36.

13. Binder G, Martin DD, Kanther I, et al. The course of neonatal cholestasis in congenital combined pituitary hormone deficiency. J Pediatr Endocrinol Metab 2007;20: 695-702. 